\title{
The Overoxidation of poly(3-hexylthiophene) (P3HT) Thin Film: CV and EIS measurements
}

\author{
Roger Gonçalves ${ }^{2}$, Ernesto C. Pereira ${ }^{2}$ and Luís F. Marchesi ${ }^{1, *}$ \\ ${ }^{1}$ Universidade Tecnológica Federal do Paraná, Av. Monteiro Lobato s/n Km 04, \\ CEP 84016-210, Ponta Grossa, PR, Brazil \\ ${ }^{2}$ Departamento de Química, Universidade Federal de São Carlos, CP 676, CEP 13565-905, São \\ Carlos, SP, Brazil \\ *E-mail: 1uismarchesi@utfpr.edu.br
}

doi: $10.20964 / 2017.03 .44$

Received: 13 December 2016 / Accepted: 17 January 2017 / Published: 12 February 2017

\begin{abstract}
In this study the electrochemical degradation of electropolymerized poly (3-hexylthiophene) (P3HT) thin film electrode was carried out by mild overoxidation conditions. Cyclic voltammetry (CV) showed the material electrochemical response lost by change in the intensity and position of the oxidation/reduction peak. Electrochemical impedance spectroscopy (EIS) showed an increase in the charge-transfer resistance $\left(\mathrm{R}_{\mathrm{ct}}\right)$ and a decrease of the low-frequency capacitance related to the load of the intercalated charge in the polymeric film. Such behavior was assigned to a hindering in the ionic intercalation/deintercalation process across the polymer/electrolyte interface, which was also corroborated by the dielectric relaxation time $\left(\tau_{0}\right)$ analysis.
\end{abstract}

Keywords: poly (3-hexylthiophene); degradation process; electrochemical impedance spectroscopy

\section{$\underline{\text { FULL TEXT }}$}

(C) 2017 The Authors. Published by ESG (www.electrochemsci.org). This article is an open access article distributed under the terms and conditions of the Creative Commons Attribution license (http://creativecommons.org/licenses/by/4.0/). 